OPEN ACCESS

Edited by:

Rajeev K. Varshney,

International Crops Research Institute

for the Semi-Arid Tropics, India

Reviewed by:

Swarup Kumar Parida,

National Institute of Plant Genome

Research, India

Caiguo Zhang,

University of Colorado, Denver, USA

*Correspondence:

Tapan K. Mohanta nostoc.tapan@gmail.com;

Hanhong Bae

hanhongbae@ynu.ac.kr

Specialty section:

This article was submitted to Plant Genetics and Genomics,

a section of the journal

Frontiers in Plant Science

Received: 25 August 2015 Accepted: 02 December 2015 Published: 24 December 2015

Citation:

Mohanta TK, Mohanta N, Mohanta YK and Bae H (2015) Genome-Wide Identification of Calcium Dependent Protein Kinase Gene Family in Plant Lineage Shows Presence of Novel $D-x-D$ and D-E-L Motifs in EF-Hand

Domain. Front. Plant Sci. 6:1146. doi: 10.3389/fpls.2015.01146

\section{Genome-Wide Identification of Calcium Dependent Protein Kinase Gene Family in Plant Lineage Shows Presence of Novel D-X-D and D-E-L Motifs in EF-Hand Domain}

\author{
Tapan K. Mohanta ${ }^{1 *}$, Nibedita Mohanta ${ }^{2}$, Yugal K. Mohanta ${ }^{3}$ and Hanhong Bae ${ }^{1 *}$ \\ ${ }^{1}$ School of Biotechnology, Yeungnam University, Gyeongsan, South Korea, ${ }^{2}$ Department Of Biotechnology, North Orissa \\ University, Baripada, India, ${ }^{3}$ Department Of Botany, North Orissa University, Baripada, India
}

Calcium ions are considered ubiquitous second messengers in eukaryotic signal transduction pathways. Intracellular $\mathrm{Ca}^{2+}$ concentration are modulated by various signals such as hormones and biotic and abiotic stresses. Modulation of $\mathrm{Ca}^{2+}$ ion leads to stimulation of calcium dependent protein kinase genes (CPKS), which results in regulation of gene expression and therefore mediates plant growth and development as well as biotic and abiotic stresses. Here, we reported the CPK gene family of 40 different plant species (950 CPK genes) and provided a unified nomenclature system for all of them. In addition, we analyzed their genomic, biochemical and structural conserved features. Multiple sequence alignment revealed that the kinase domain, auto-inhibitory domain and EF-hands regions of regulatory domains are highly conserved in nature. Additionally, the EF-hand domains of higher plants were found to contain four D-x-D and two D-E-L motifs, while lower eukaryotic plants had two D-x-D and one D-x-E motifs in their EF-hands. Phylogenetic analysis showed that CPK genes are clustered into four different groups. By studying the CPK gene family across the plant lineage, we provide the first evidence of the presence of D-X-D motif in the calcium binding EF-hand domain of CPK proteins.

Keywords: CPK, CaM, CBL, calcium signaling, evolution, EF-hands

\section{INTRODUCTION}

Plants are constantly challenged by different environmental factors that guide regulation of various physiological and developmental programs in a systematic manner (Choi et al., 2014). Plants sense and process environmental stimuli such as light, temperature, water and nutrients to enable normal growth and development (Krouk et al., 2011; Davidson and Gu, 2012; Lawson et al., 2014; Matos et al., 2014). Plant cells are able to respond to external stimuli in a time dependent manner, after which they process the information received. This is followed by signal transduction and finally appropriate physiological responses (Asano et al., 2005; Clouse, 2011; Tena et al., 2011; Huang et al., 2012; Boudsocq and Sheen, 2013; Wasternack and Hause, 2013). The propagation and amplification of signals involve rapid changes in cellular and sub-cellular levels of signals by second messengers that relay information to downstream effector molecules such as enzymes, transcription 
factors, and cytoskeletal proteins, which are responsible for changes in gene expression, metabolic activity and developmental patterns (Mohanta et al., 2012; Kanchiswamy et al., 2013). Among these messengers, calcium dependent protein kinases (CPKs) are the most important enzymes responsible for a diverse array of plant growth and development, as well as biotic and abiotic stress responses (Luan, 2009; Kanchiswamy et al., 2013; Mohanta et al., 2015b).

Calcium ion is considered an ubiquitous second messenger in eukaryotic signal transduction pathways (Hamel et al., 2014). Intracellular $\mathrm{Ca}^{2+}$ concentrations are modulated by various signals (e.g., hormones, biotic and abiotic stresses) and play significant roles in plant growth and development and stress responses (Dodd et al., 2010; Reddy et al., 2011; Mohanta and Bae, 2015). CPKs are considered novel calcium sensors that act as crucial mediators in response to diverse stress conditions (Cheng et al., 2002; Schulz et al., 2013). The genes encoding CPKs are found in plants as multi-gene family members (Harmon et al., 2001). The CPKs are classified as serine/threonine protein kinases that contain five domains: (i) N-terminal variable domain, (ii) kinase domain, (iii) auto-inhibitory domain, (iv) regulatory domain, and (v) C-terminal variable domain (Harmon et al., 2001). The regulatory domain contains four calcium binding EF-hands, and the conserved glutamic acid (E) and aspartate (D) amino acids present in the EF-hands act as an important calcium sensor (Day et al., 2002; Hrabak et al., 2003). The EFhands, which act in pairs, are divided into $\mathrm{N}$-and $\mathrm{C}$-terminal EFhand pairs. The EF-hand motif is highly conserved and contains a 12 amino acids helix-loop-helix structure that coordinates the calcium ion. The EF-hand module binds $\mathrm{Ca}^{2+}$ ion in the loop and undergoes conformational changes that result in the exposure of hydrophobic pockets, which facilitates proteinprotein interactions with a variety of downstream interacting partners (Harmon et al., 2000; Sulmann et al., 2014). The N- and C-terminal domains of CPKs are highly variable in nature and contain myristoylation and palmitoylation sites for sub-cellular targeting, whereas the kinase domain is catalytic in nature and contains an ATP binding site (Ito et al., 2010). While CPKs are regulated by diverse mechanisms, sensitivity to calcium ion can be influenced by the type of substrate, and each isoform of CPKs responds to a specific set of calcium signals.

There are several gene families that act as potential calcium sensors in plants including calcium dependent protein kinase $(C P K)$, calmodulin $(C a M)$, calmodulin like $(C M L)$, calcineurin B-like (CBL), and CPK related kinase (CRK) (Hrabak et al., 2003). Among these calcium sensor genes, CPKs are unique in that they contain both a kinase catalytic domain and an EF-hand containing calcium binding domain, which leads to signaling and sensor activity in a single gene product (Harmon et al., 2000). The fusion of the kinase domain with an EF-hand containing regulatory domain probably arose via early fusion of an upstream protein kinase with downstream CaM to conduct immediate and efficient downstream phosphorylation of target proteins.

To date, there has been little information available regarding the unified nomenclature, genomics, biochemistry and conserved structures of $C P K$ genes in plants. Therefore, in this study, we conducted large scale identification of $C P K$ gene family members using 40 different plant species (950 CPK genes). Additionally, we provided a unified nomenclature system and analyzed the conserved structural and functional aspects of CPKs (Ouyang et al., 2007; Goodstein et al., 2012; Lamesch et al., 2012; Nystedt et al., 2013).

\section{MATERIALS AND METHODS}

\section{Identification of CPK Genes}

To understand the signature motif of the CPK gene family in plants, genome-wide identification of $C P K$ gene family members of 40 plant species was conducted. The CPK genes from Arabidopsis thaliana were downloaded from "The Arabidopsis Information Resources" (TAIR) database (Lamesch et al., 2012), while the $C P K$ genes from rice were downloaded from the "rice Genome Annotation Resources" (http://rice.plantbiology.msu. edu/) database (Ouyang et al., 2007). The CPK protein sequences from Arabidopsis thaliana and Oryza sativa were used as search queries in the publicly available phytozome database (http:// www.phytozome.net/) (Goodstein et al., 2012) and P. abies genome database (http://congenie.org/start) (Nystedt et al., 2013) to identify the CPK genes from other plant species. In total, 40 species were included in this study (Table 1). The BLASTP search was conducted to identify the $C P K$ gene family members of unknown species by taking the protein sequences of AtCPKs and OsCPKs. All CPK proteins of the 40 species were analyzed using the SCAN PROSITE software with default parameters to confirm the presence of all the domains of CPKs (de Castro et al., 2006). Only CPK proteins that contained the kinase domain, autoinhibitory domain, and regulatory domain with four calcium binding EF-hands was considered for further investigation. All the CPK proteins identified from these approaches were again subjected to BLASTP searches against the TAIR and rice genome annotation database to confirm the BLAST hits with CPK genes of Arabidopsis thaliana and Oryza sativa. The palmitoylation sites of all CPK proteins were identified by CSS Palm software version 2.0 (Ren et al., 2008). The molecular masses of all CPK proteins were predicted using protein calculator version 3.3 (http://www. scripps.edu/ cdputnam/protcalc.html).

\section{Nomenclature of CPKs}

In the traditional nomenclature system, numbers have been assigned to $C P K$ genes according to the serial number in which they are cloned and identified. However, this nomenclature system makes it difficult to determine the exact function of the orthologous counterpart. Plant genomic data are currently increasing daily; therefore, it is necessary to provide a unique and systemic nomenclature to all the CPK genes. The development of a new nomenclature system can provide brief functional information regarding the orthologous $C P K$ genes in other organisms. Therefore, an orthologous based nomenclature system was used to assign the name to each $C P K$ gene of the studied organisms as proposed by different research groups (Supplementary Table 1; Hamel et al., 2006; Kanchiswamy et al., 2013; Mohanta and Mohanta, 2013; Mohanta et al., 2014, 2015a). The Arabidopsis thaliana and Oryza sativa CPK genes were taken as the orthologous genes for this purpose (Hamel et al., 
TABLE 1 | Genome size of different plant species used in this study and number of CPK genes present in their respective genomes.

\begin{tabular}{|c|c|c|c|c|c|}
\hline SI. No & Name of species & Type of organism & Genome size (Mbs) & Total no. of loci/genome & Total no. of CPK genes/genome \\
\hline 1 & Aquilegia coerulea & Dicot & 302 & 24823 & 16 \\
\hline 2 & Arabidopsis thaliana & Dicot & 135 & 27416 & 34 \\
\hline 3 & Brachipodium distachyon & Monocot & 272 & 31694 & 27 \\
\hline 4 & Brassica rapa & Dicot & 283.8 & 40492 & 49 \\
\hline 5 & Capsella rubella & Dicot & 134.8 & 26521 & 32 \\
\hline 6 & Carica papaya & Dicot & 135 & 27332 & 15 \\
\hline 7 & Chlamydomonas reinhardtii & Lower eukaryote & 111.1 & 17741 & 14 \\
\hline 8 & Citrus clememtina & Dicot & 301.4 & 24533 & 26 \\
\hline 9 & Citrus sinensis & Dicot & 319 & 25376 & 24 \\
\hline 10 & Coccomyxa subellipsoidea & Lower eukaryote & 49 & 9629 & 2 \\
\hline 11 & Cucumis sativus & Dicot & 203 & 21494 & 18 \\
\hline 12 & Eucalyptus grandis & Dicot & 691 & 36376 & 22 \\
\hline 13 & Fragaria vesca & Dicot & 240 & 32831 & 14 \\
\hline 14 & Glycine max & Dicot & 975 & 54175 & 41 \\
\hline 15 & Gossipium raimondi & Dicot & 761.4 & 37505 & 40 \\
\hline 16 & Linum usitatissimum & Dicot & 318.3 & 43471 & 47 \\
\hline 17 & Malus domestica & Dicot & 881.3 & 63514 & 28 \\
\hline 18 & Manihot esculenta & Dicot & 532.5 & 34085 & 26 \\
\hline 19 & Medicago truncatula & Dicot & 241 & 50894 & 11 \\
\hline 20 & Micromonas pusila CCMP1545 & Lower eukaryote & 22 & 10660 & 2 \\
\hline 21 & Mimulus guttatus & Dicot & 321.7 & 26718 & 25 \\
\hline 22 & Oryza sativa & Monocot & 372 & 39049 & 30 \\
\hline 23 & Ostreococcus lucimarinus & Lower eukaryote & 13.2 & 7796 & 3 \\
\hline 24 & Panicum virgatum & Monocot & 1358 & 98007 & 53 \\
\hline 25 & Phaseolus vulgaris & Dicot & 521.1 & 27197 & 25 \\
\hline 26 & Physcomitrella patens V.13 & Bryophyte & 480 & 33362 & 25 \\
\hline 27 & Picea abies & Gymnosperm & 1960 & 28354 & 11 \\
\hline 28 & Populus trichocarpa & Dicot & 422.9 & 41335 & 28 \\
\hline 29 & Prunus persica & Dicot & 227.3 & 26873 & 17 \\
\hline 30 & Ricinus communis & Dicot & 400 & 31221 & 15 \\
\hline 31 & Selaginella moellendorffii & Pteridophyte & 212.5 & 22273 & 9 \\
\hline 32 & Setaria italica & Monocot & 405.7 & 35471 & 27 \\
\hline 33 & Solanum lycopersicum & Dicot & 900 & 34727 & 28 \\
\hline 34 & Solanum tubersum & Dicot & 800 & 35119 & 21 \\
\hline 35 & Sorghum bicolor & Monocot & 697.5 & 33032 & 28 \\
\hline 36 & Thellungiella halophila & Dicot & 238.5 & 26351 & 31 \\
\hline 37 & Theobroma cacao & Dicot & 346 & 29452 & 17 \\
\hline 38 & Vitis venifera & Dicot & 487 & 26346 & 17 \\
\hline 39 & Volvox carteri & Lower eukaryote & 125.4 & 14971 & 6 \\
\hline 40 & Zea mays & Monocot & 2500 & 63540 & 47 \\
\hline
\end{tabular}

2006; Schlicker et al., 2006). In this study, the nomenclature system adopted for naming Arabidopsis, poplar and rice mitogenactivated protein kinases (MPKs) was extended to other genes (Hamel et al., 2006; Mohanta et al., 2015a). For each CPK gene, a name was assigned by taking the first letter of the genus and the first letter of the species, after which $C P K$ and the orthology based number of Arabidopsis thaliana or Oryza sativa were used. In the nomenclature system, the first letter of the genus was kept upper case and the first letter of the species was kept lower case. When the first letter of the genus and species coincided with one another, only the first letter of the genus and the first, second, third or later letter of the species name was considered in conjunction with the suitability of pronunciation. For example, C. rubella and C. reinhardtii share " $C$ " as first letter of the genus and " $r$ " as the first letter of the species. In this case, C. rubella $C P K s$ were named $C r C P K$, while $C$. reinhardtii $C P K s$ were named CreinCPK. The monocot specific CPKs were named according to Oryza sativa, while the rest of $C P K s$ were named according to Arabidopsis thaliana. This nomenclature system can be useful to provide a unique identity to each $C P K$ gene throughout the 
plant kingdom. The sequence/structural similarities resemble the functional similarities of genes (Aravind et al., 2002; Schlicker et al., 2006; Li et al., 2008). Specifically, the unique orthologous gene of one species may resemble the other gene and undergo similar cellular function. A similar approach is being used to predict potential function of newly sequenced genes and their gene products. It is nearly not possible to study the role of each $C P K$ with different functional aspects. Therefore, an orthology based nomenclature system of $C P K$ genes will provide basic information regarding its ortholog counterpart (Wright and Bruford, 2006).

\section{Multiple Sequence Alignment}

The CPK protein sequences of plants were subjected to multiple sequence alignment to identify the conserved domains and motifs. Multiple sequence alignment was carried out using the Multalin software (http://multalin.toulouse.inra.fr/ multalin/). The statistical parameters used to carry out multiple sequence alignment were as follows: protein weight matrix, BLOSUM62-12-2; gap penalty at opening, default; gap penalty at extension, default; gap penalty at extremities, none; one iteration only, no; high consensus value, $90 \%$ (default); and low consensus value $50 \%$ (default).

\section{Construction of Phylogenetic Tree}

All the protein sequences of CPKs were subjected to multiple sequence alignment in clustal omega to generate a clustal file. The generated clustal file of CPKs was converted to MEGA file format using the MEGA6 software and then used to construct the phylogenetic tree using the same software (Tamura et al., 2013). Different statistical parameters used to construct the phylogenetic tree were; statistical method, maximum likelihood; test of phylogeny, bootstrap method; number of bootstrap replication, 5000; model/method, Jones-Taylor-Thornton; rates among sites, uniform; gaps/missing data treatment, partial deletion; site coverage cutoff, $95 \%$; and branch swap filter, very strong.

\section{Statistical Analysis}

Tajima's relative rate test was conducted to understand the rate of evolution of plant CPKs. To accomplish this, MEGA6 software was used to conduct Tajima's relative rate test and Tajima's test of neutrality of the CPKs in MEGA file that used to generate the phylogenetic tree. The statistical parameters used for Tajima's relative rate test were; analysis, Tajima's relative rate test; scope, for three chosen sequences; substitution type, amino acids; gaps/missing data treatment, complete deletion. Tajima's test of neutrality was carried out to understand the polymorphism of $C P K$ genes in plants. The statistical parameters used to carry out Tajima's test of neutrality were: analysis, Tajima's neutrality test; scope, all selected taxa; substitution type, amino acids; and gaps/missing data treatment, complete deletion.

Correlation regression analysis (http://www.mathportal. org/calculators/statistics-calculator/correlation-and-regressioncalculator.php) and paired $t$-test (http://www.mathportal. org/calculators/statistics-calculator/t-test-calculator.php) was conducted using online tool Math Portal. In both the analysis, genome size was provided in $\mathrm{X}$-axis and CPK gene family size was provided in Y-axis. The paired $t$-test was conducted at significance level of $p<0.001$.

\section{RNA ISOLATION AND qRT-PCR}

Wild type Brassica rapa L. sub species oleifera were grown in soil in greenhouse under $16 \mathrm{~h}$ light and $8 \mathrm{~h}$ dark cycle at $22-25^{\circ} \mathrm{C}$ for 20 days. Cold treatment was conducted by subjecting the plants to $4^{\circ} \mathrm{C}$ and drought/heat treatment was applied at $37^{\circ} \mathrm{C}$. Treated plant leaves were immediately transferred to liquid nitrogen for further analysis. All experiments were carried out in triplicates. Total RNA was isolated from treated and control samples using Trizol reagent. RNA was treated with RNase free DNAase to ensure that there is no DNA contamination in the RNA sample. First strand cDNA synthesis was carried out using a Fermentas RevertAid first strand cDNA synthesis kit according to the manufacturer's instruction. The primers for the $B$. rapa $C P K$ genes were designed using primer3 software targeting either the extreme $5^{\prime}$ end (extreme $5^{\prime}$ ends are not conserved) or $3^{\prime}$ UTR region which produced an amplicon of 120-200 bp (primer length between 20 and $24 \mathrm{bp}$ ) with a melting temperature of $58-60^{\circ} \mathrm{C}$ (Supplementary Table 2). The primer lengths were kept around 18-22 nucleotides. Quantitative real-time PCR was conducted using a Mx3000P real-time PCR system with SYBR green master mix $(2 x)$ (Fermentas) and ROX as the passive reference standard to normalize the SYBR fluorescent signal. PCR amplification was conducted in a $25 \mu \mathrm{l}$ reaction mixture containing $1 \mu \mathrm{l} \mathrm{cDNA}$ as template, $12.5 \mu \mathrm{l}$ SYBR green master mix $(2 x), 1 \mu l$ of each forward and reverse primer and nuclease free water up to $25 \mu \mathrm{l}$. The thermal profile for quantitative real time PCR reaction was; initial activation at $95^{\circ} \mathrm{C}$ for $10 \mathrm{~min}$, followed by 40 cycles of $95^{\circ} \mathrm{C}$ for $30 \mathrm{~s}$, $60^{\circ} \mathrm{C}$ for $30 \mathrm{~s}$, and $72^{\circ} \mathrm{C}$ for $30 \mathrm{~s}$. Each quantitative real time PCR was carried out in triplicate on three biological replicates. Primers showing efficiency between 90-105\% were considered significant. Relative expression was calculated using ACT2 as the reference gene. The relative expression of $B r C P K$ genes was calculated using the $2^{-\Delta \Delta C T}$ method (Schmittgen and Livak, 2008).

\section{RESULTS AND DISCUSSION}

\section{Larger the Genome Size is Not Directly Proportional to Bigger the Gene Family}

Angiosperms are considered as the most advanced groups of land plants. Although the CPKs of several angiosperms have been widely investigated, such studies have been limited to specific species (Hrabak et al., 2003; Asano et al., 2005; Kanchiswamy et al., 2013; Kong et al., 2013; Zuo et al., 2013; Liu et al., 2014). Therefore, very little information is known about their different genomic aspects. We found that genome size and presence of the $C P K$ gene number vary from species to species (Table 1). Among the investigated plants, Ostreococcus lucimarinus has the smallest genome (13.2 Mbs), while Zea mays has the largest (2500 Mbs). The genome of Coccomyxa subellipsoidea encodes the lowest 
number of CPK genes (2), while the genome of Panicum virgatum encodes the highest (53) among the studied species. In this study we found that, the larger genome size is not directly proportional to a larger gene family. The CreinCPK17-5 (Chlamydomonas reinhardtii) is the largest $C P K$, containing an ORF of 5940 nucleotides (1979 amino acids), while CPCPK2 (Carica papaya) is the smallest $C P K$, with an ORF length of 693 nucleotides (231 amino acids; Supplementary Table 1). Correlation regression analysis of $C P K$ genes compared to the genome size didn't result any linear correlation (Figure 1). Eleven species were found to be clustered within size of 10-20 CPK members and 14 species were found to be clustered with size of 20-30 CPK members (Figure 1). The regression coefficient analysis was found to be $r=0.4487$. The regression coefficient should be $+1 /-1$ to infer a direct correlation between the genome size and the size of gene family. The paired $t$-test between the genome size and gene family size differs significantly at $p<0.001$. The $t$-value was found to be 5.9796 with degree of freedom 40 and critical value 3.551. The average size of CPK genes of green algae and Physcomitrella patens is larger than those of advanced higher plants. The extra sequences of lower eukaryotic plants are probably deleted during evolution from lower eukaryotes to higher eukaryotes owing to the need to adapt to terrestrial habitats (Rensing et al., 2008). These findings indicate that evolution of CPK genes occurred via loss of gene size; hence, higher plants do not contain extra sequences. Further genomic analysis revealed that, many $C P K$ genes contain either 6,7 , or 8 introns with a maximum of 11 introns in at least one gene, except for Carica papaya, Ostreococcus lucimarinus, and Ricinus communis (Supplementary Table 1). No introns were detected in some of the CPK genes of O. lucimarinus and P. patens. The O. lucimarinus is a lower aquatic algae and $P$. patens is the first land plant, explaining their conserved and ancient origin (Palenik et al., 2007; Jain et al., 2008; Rensing et al., 2008). The molecular masses of CPKs were reportedly vary from $40 \mathrm{kD}$ to $90 \mathrm{kD}$ (Martín and Busconi, 2001; Tuteja and Mahajan, 2007); however, we found that, they ranges from $26.134 \mathrm{kD}$ (CpCPK2) to $198.916 \mathrm{kD}$ (CreinCPK17-5). The isoelectric point of CPKs ranges from 4.61 (PaCPK33, OlCPK3) to 9.33 (AtCPK16) (Supplementary Table 3). The analysis of amino acid composition of CPKs showed that, leucine (L) was present most frequently (8.46 times per CPK) (Supplementary Table 4), while tryptophan (W) was present least frequently (0.91 times per CPK). Aspartic acid (D) and glutamic acid (E), which were responsible for calcium sensing, were found to be 7.14 and 7.83 times per CPK, respectively (Supplementary Table 4).

These finding indicates that, when more energy is required to synthesize a particular amino acid, there is less chance of that amino acid occurring more frequently (Akashi and Gojobori, 2002). The average abundance of $\mathrm{T}$ in CPK is only 0.91 times per $\mathrm{CPK}$, and the energy required to synthesize $\mathrm{W}$ is 74.3. High energy input is required to synthesize $\mathrm{W}$; therefore, the CPK protein can only incorporate $0.91 \mathrm{~W}$ per $\mathrm{CPK}$. The energy required to synthesize $\mathrm{D}$ and $\mathrm{E}$ is 12.7 and 15.3 unit, respectively (Akashi and Gojobori, 2002); accordingly, the plants can able to accommodate $7.14 \mathrm{D}$ and $7.83 \mathrm{E}$ per CPK.

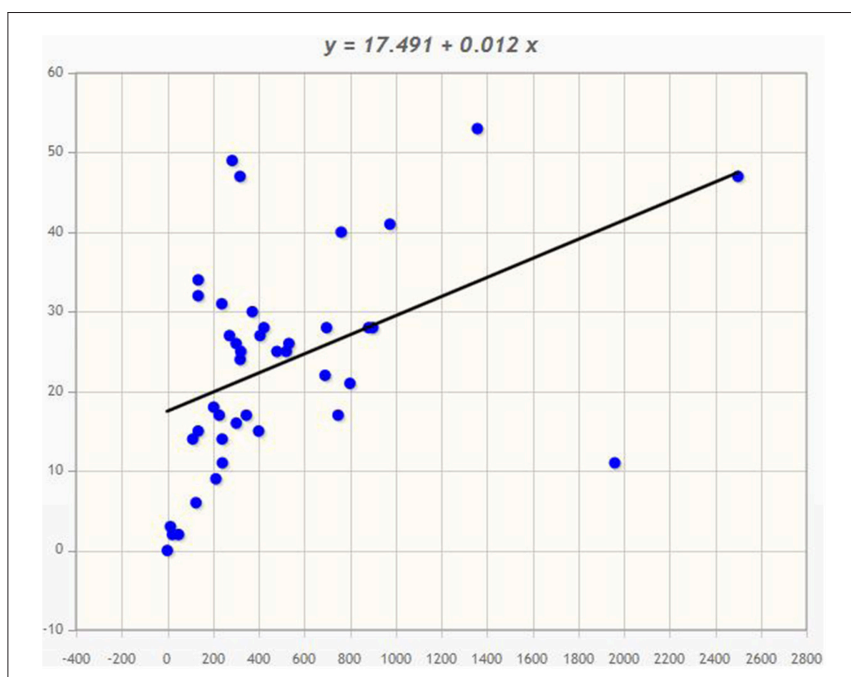

FIGURE 1 | Correlation regression analysis of Genome size and CPK gene family size. The correlation regression analysis shows, the genome size of an organism is not directly proportional to the size of the gene family. The bigger the genome size isn't directly proportional to the bigger the gene family. In the majority of cases, plant encodes 10-30 CPKs per genome. The X-axis denotes the genome size and $Y$-axis denotes the CPK gene family size.

\section{CPKs Contains Four Conserved D-X-D Motifs in EF-Hand Domain}

Even though many studies have been carried out, no specific conserved domain/motif has been reported for kinase domains, auto-inhibitory domain and EF-hand domains of the CPK protein. We believe, this is the first report showing the presence of conserved domains/motifs in CPKs. To identify the conserved domains/motifs, multiple sequence alignments of monocot, dicot and lower eukaryotic plants were carried out separately. We found that, monocot and dicot plants shared some common conserved sequences in the kinase domains, C-x-G-G-E-L-X-DR-I, H-R-D-L-K-P-E-N-F-L, D-X-V-G-S-X-Y-Y, A-P-E-V-L, DV/I-W-S, G-V-I-x-Y-I-L-L, G-X-P-P-F-W, P-W-P-x-I-S, A-KD-L-V, and H-P-W (Figure 2, Table 2, Supplementary Table 5, Supplementary Figures 1-3), while the kinase domain of lower eukaryotic plants such as $C$. reinhardtii, $V$. carteri, $M$. pusila, O. lucimarinus, and $P$. patens contains little bit different conserved sequences, M-E-L-C-X-G-G-E-L-F, H-R-D-L-K-P-EN-F-L, D-F-G-L-S-V/x, A-P-E-V-L/x, D-I-W-S-X-G-V, and P-FW (Supplementary Table 5, Supplementary Figure 4).

The conserved sequences D-x-V-G-S-x-Y-Y, G-V-I-x-Y-I-LL, G-X-P-P-F-W, P-W-P-X-I-S, A-K-D-L-V, and H-P-W present in higher plants are absent from the kinase domain of lower eukaryotic plants (Supplementary Table 5). Earlier it was thought that, auto-inhibitory domain does not have any conserved sequence. But, we found that, the auto-inhibitory domains of monocot, dicot and lower eukaryotic plants are also highly conserved in nature. The common conserved domains present in the auto-inhibitory domains of monocot and dicot plants are K-P-L-D, F-S-A-M-N-K-L, and A-L-X-XI-A (Figure 3A, Supplementary Table 6). The auto-inhibitory domain of lower eukaryotic plants doesn't contain K-P-L-D and 
LuCPK2-1

CsatcPK1

OsCPK 27

ThCPK2

LuCPK2-1
CsatCPK1
OsCPK27
ThCPK2

LuCPK2-1

CsatcPK1

OsCPK 27

ThCPK2

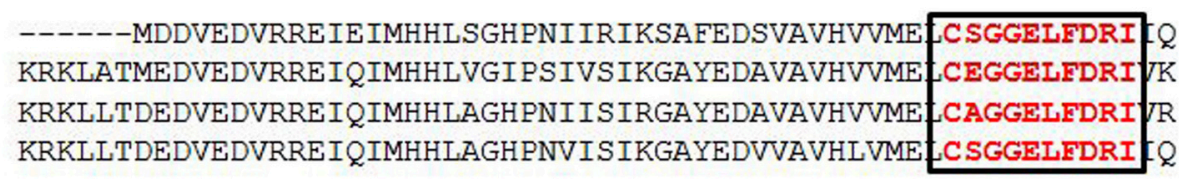

KGHYTERKAAEITRTIFGVVEACHSLGV MHRDIKPENELF IDEHEDSPLKAIDFGLSIFF LGHYTERQAAELART I IGVIEACHSLGV IHRDLKPENELF VDSREDSPLKAIDFGLSIFF KGHYTERQAAGLARVIVAVVESCHSLGV MHRDLKPENFLF VGNEEDAPL KT IDFGLSMFF RGHYTERKAAELARTIVGVLETCHSLGV MHRDLKPENELF JSKEEDSLLKTIDFGLSMFF

LuCPK2-1
CsatCPK1
OsCPK27
ThCPK2

\begin{tabular}{|c|c|c|c|}
\hline KPGQIF & JDVVGSPYYVAPEVL KKYGPE & ADVWSAGVMVYILLSGVPPEWA & \\
\hline KPGDIF & DDVVGSPYYVAPEVL KLYGPE & DVWSAGVMIYILLSGVPPEWA & \\
\hline RPGEVE & PDVVGSPYYVAPEVL KSYGQE & DVWSAGVIIYILICGVPPEWA & \\
\hline PDEVE & EDVVGSPYYVAPEVL KKRYGPE & DVWSAGVIVYILLSGVPPEWA & \\
\hline
\end{tabular}

\begin{tabular}{|c|c|c|c|c|c|}
\hline DEIFHEVLHGNPI & PWPHVS & AKELV & KKMLVREPNKRITTHEVLC & HPW & REDGVAP \\
\hline QEIFDEVLHGDLD & PWPSIS & AKDIV & RKMLIRNPKERLTAHEVLC & HPW & QVDGMAP \\
\hline QGIFEQVL & PWRNVS & AKDIL & KKVLRDPKKRLTAH & HPW & QMSGSAP \\
\hline QGIFEQVLHGDLDF & PWPSIS & AKXIV & KKMLVRDPKRRLTAHQVLC & HPW & FQIDGVAP \\
\hline
\end{tabular}

FIGURE 2 | Presence of conserved domains in the kinase domain of plant calcium-dependent protein kinases (CPKs) (red). The major conserved domains are C-S-G-G-E-L-F-D-R-I, H-R-D-L-K-P-E-N-F-L-F, D-V-V-G-S-P-Y-Y, A-P-E-V-L, D-V-W-S, G-V-M-V-Y-I-L-L, G-V-P-P-F-W, P-W-P-H-V-S, A-K-E-L-V, and $\mathrm{H}-\mathrm{P}-\mathrm{W}$. The complete details describing the conserved domains of CPKs are provided in the Supplementary Figures.

A-L-X-X-I-A domains and only contains the A-M-N-K-L domain (Supplementary Table 6).

The EF-hands of CPK bind the calcium ions and play a significant role in gene regulation (Valmonte et al., 2014). The $\mathrm{Ca}^{2+}$ ion binds to either $\mathrm{D}$ or $\mathrm{E}$ amino acid of the EF-hand which leads the auto-inhibitory domain being released from the kinase domain, and subsequent gene regulation (Hwang et al., 2000; Weljie et al., 2003; Tuteja and Mahajan, 2007; DadaczNarloch et al., 2011; Boudsocq and Sheen, 2013). Therefore, the presence of $\mathrm{D}$ or $\mathrm{E}$ amino acid in the EF-hand is very crucial. The EF-hand containing the regulatory domains of CPKs is also highly conserved in nature. The monocot and dicot plants share some common motifs in their EF-hand domain which are; EE-I/x, D-X-D, D/E-E-L, D-Y-X-E-F, F-D-x-D, E-E-L, D-G-X-I, and $\mathrm{Y}-\mathrm{x}-\mathrm{E}-\mathrm{F}-\mathrm{X}-\mathrm{X}-\mathrm{M}-\mathrm{M}$ (Figure 3A, Table 2, Supplementary Table 5). Additionally, one extra domain $\mathrm{E}-\mathrm{D}-\mathrm{x}_{(4)}-\mathrm{A}-\mathrm{F}$ is conserved in monocot plants which is absent in dicot plants. The lower eukaryotic plants possess only one $\mathrm{D}-\mathrm{x}-\mathrm{D}$ and $\mathrm{D}-\mathrm{x}-\mathrm{x}-\mathrm{E}$ motif in their EF-hand domain. The monocot and dicot (higher eukaryotes) plants possess at least four D-x-D (one D-x-D motif in each EF-hand) and two D/E-E-L motifs in their EF-hands, while lower eukaryotes contain only two D-x-D and one D-x-x-E motifs in their EF-hands (Supplementary Table 5). The two D-x$\mathrm{D}$ motifs of lower eukaryotic plants are present only in the third and fourth EF-hands. Instead of presence of D-x-D and D/EE-L motifs in CPKs, they also found to contain some substitute motifs like x-D/E-L, Q-E-L (BdCPK30, PvCPK30-1, PvCPK30-2,
SiCPK30, SbCPK30, and OsCPK9) and E-E-F/M (BdCPK72, PvCPK8-2, SiCPK7-1, SbCPK8-1, ZmCPK8-1, ZmCPK32-1, OsCPK8, PvCPK7-1, BdCPK16-2, OsCPK3, OsCPK4, SiCPK16, SbCPK28, ZmCPK16-1/2, and PvCPK16-2) (Supplementary Table 7). Earlier, Cheng et al. (2002) reported that EF-hands are most conserved at position 1 and 2, while they are least conserved at position 4 (Cheng et al., 2002). In this study, we found that, in the first EF-hand of higher eukaryotic plants (monocot and dicot), the E-E-I/x motif is conserved at position 1, 2, and 3 (Figure 3A). However, all the four EF-hands contain the $\mathrm{D}-\mathrm{x}-\mathrm{D}$ motif at position 14,15 , and 16 and the D/E-E-L motif is at position 24, 25, and 26 respectively (Figures $\mathbf{3 A}, \mathbf{B}$, 4). The first EF-hand contains an E-M-F motif at position 8, 9, and 10. In the second EF-hand, there is an E-x-E motif at position 3, 4, and 5, while in the third EF-hand; the x-E-D motif is present at position 3 and 4 . In the fourth EF-hand, there is no conserved amino acid at position 1,2 , or 3 but there is presence of a conserved $\mathrm{D} / \mathrm{E}$ residue at position 11 and 12. According to our findings, the conserved domains/motifs at position14, 15, 16, 24, 25, and 26 are crucial for all EF-hands that are responsible for $\mathrm{Ca}^{2+}$ binding. The specific conserved motif E-E-I/x at position 1,2 , and 3 and E-M-F at position 8, 9, and 10 are first EF-hand specific (Figure 3A). The E-X-E motif at position 3, 4, and 5 is second EF-hand specific, while the $\mathrm{x}-\mathrm{E}-\mathrm{D}$ motif at position 3 and 4 is third EF-hand specific (Figure 3A). The presence of conserved D/E amino acids at position 11 and 12 is fourth EF-hand specific. The presence of the 
TABLE 2 | Presence of conserved motifs in EF-hands of CPKs.

Conserved motifs in EF-hands

\begin{tabular}{|c|c|c|c|}
\hline Monocot & Dicot & Lower eukaryotes & Altogether \\
\hline$E-E-1 / x$ & $E-E-1 / x$ & & $E-E-1 / x$ \\
\hline E-M-F & E-M-F & & \\
\hline \multirow[t]{2}{*}{$D-x-D$} & $D-x-D$ & & $D-x-D$ \\
\hline & $G-x-1$ & & $G-x-1$ \\
\hline \multirow[t]{2}{*}{ D-E-L } & D/E-E-L & & D-E-L \\
\hline & $D / E-x-E$ & & $D-E-x-E$ \\
\hline$D-x-D$ & $D-x-D$ & $D-x-D$ & $D-x-D$ \\
\hline$D-x-x-E-F$ & $D-Y-X-E-F$ & $D-x-x-E$ & $E-F-I-x$ \\
\hline \multicolumn{4}{|l|}{$E-D-x_{(4)}-A-F$} \\
\hline \multirow[t]{3}{*}{ F-D-X-D } & F-D-X-D & & $D-x-D$ \\
\hline & & & $G-x-1$ \\
\hline & $G-I-x-Y$ & & \\
\hline E-E-L & D-E-L & & D-E-L \\
\hline$D-x-D$ & $D-x-D$ & $D-x-D$ & E-D-x-D \\
\hline$D-G-x-1$ & $D-G-R / x-1$ & & $D-x-D / G-x-1$ \\
\hline Y-X-E-F-X-X-M-M & Y-x-E-F-X-X-M-M & & $Y-x-E-F-x-x-M-M$ \\
\hline
\end{tabular}

Monocot and dicot plants share common E-E-I/X, E-M-F, and D-X-D motifs in EF-hands. Higher plants contain $4 D-x-D$ motifs in their EF-hands, while lower eukaryotes have only two $D-x-D$ motifs.

conserved of CPK motifs from lower to higher plants explains the homologous nature of gene evolution (Thornton and DeSalle, 2000). All EF-hands shows the differences in their first, second, third and fourth amino acid positions. When compared to higher eukaryotes, lower eukaryotes possess only two D-x-D motifs at the second and third EF-hand (Supplementary Table 5). These $\mathrm{D}$-x-D motifs are also present in position 14,15 , and 16 of the second and third EF-hands in lower eukaryotic plants. Some of the lower eukaryotes contain an E-E-I/x motif at the first EFhand. In the first and fourth EF-hands of lower eukaryotes, D is conserved at position 14, while in the second EF-hand, D and $\mathrm{E}$ are conserved at position 22 and 25, respectively. These differences in numbers and positions of EF-hands are likely cause variations in the allosteric properties of the $\mathrm{Ca}^{2+}$ binding and activation threshold (Hrabak et al., 2003). The number of EFhand is very important to determine the $\mathrm{Ca}^{2+}$ regulation in $\mathrm{CPK}$ activity. Site directed mutagenesis of conserved $\mathrm{E}$ residues in each EF-hand showed that, a closer proximity of the EF-hand to the auto-inhibitory domain shows an effect on $\mathrm{Ca}^{2+}$ regulation (Zhao et al., 1994).

\section{CPKs Contains Membrane Targeting Palmitoylation and Myristoylation Sites}

Very little information is available regarding the $\mathrm{N}$-terminal variable domain of CPK. It has been reported that, the $\mathrm{N}$-terminal variable region contains sub-cellular targeting information (Harmon et al., 2000; Curran et al., 2011). However, none of the 34 Arabidopsis CPKs are predicted to be integral membrane proteins (Cheng et al., 2002). Despite the variability at the $\mathrm{N}$ terminal domain, most CPKs have a $\mathrm{G}$ residue at the second position and a $\mathrm{C}$ residue at $3,4,5$, and 6 positions. This $\mathrm{N}$-terminal $\mathrm{G}$ residue undergoes modification by myristic acid which is known as myristoylation (Smotrys and Linder, 2004). The N-myristoylation has been reported to promote proteinmembrane attachment and protein-protein interactions (Cheng et al., 2002). The mutation of the $\mathrm{N}$-terminal $\mathrm{G}$ residue abolishes lipid modification and prevents membrane association (Martín and Busconi, 2001). Among the 950 CPKs, 844 have the $\mathrm{G}$ residue at the second position (Table 3). In Arabidopsis it has reported that, the $\mathrm{N}$-terminal G residue of AtCPK2 is myristoylated, and the first ten amino acids of CPKs are known to be critical for localization to the endoplasmic reticulum (ER) membrane (Lu and Hrabak, 2002). The second lipid modification leads to addition of palmitate to the $\mathrm{C}$ residue at position 3 , 4 , or 5 of the N-terminal region of CPKs (Cheng et al., 2002). Some major conserved palmitoylation motifs of CPKs found during this study were M-G-C, M-G-N-C, M-G-N-C-C, M-G-N-T$\mathrm{C}-\mathrm{V}$, and $\mathrm{M}-\mathrm{G}-\mathrm{N}-\mathrm{C}-\mathrm{C}-\mathrm{R}$ (Table 3). Both myristoylation at the $\mathrm{N}$-terminal $\mathrm{G}$ residue and palmitoylation at the $\mathrm{N}$-terminal $\mathrm{C}$ residues at position 4 and 5 have been validated experimentally in membrane bound OsCPK2 (Martín and Busconi, 2001). When myristoylation of OsCPK2 was abolished by mutating N-terminal $\mathrm{G}$ amino acid, the protein could no longer be palmitoylated, indicating that, myristoylation might be the prerequisite to palmitoylation (Martín and Busconi, 2001).

\section{Phylogenetic Analysis Shows CPKs are Grouped into Four Groups}

In this study, we constructed an unrooted phylogenetic tree of CPKs from monocot, dicot and lower eukaryotic plants (Figure 5). The result revealed that CPK genes fell into four different groups; group A (red), B (blue), C (fuschia), and D (purple) (Figure 5). Previous studies by different researchers also reported the presence of four groups in CPKs ( $\mathrm{Lu}$ and Hrabak, 2002; Hamel et al., 2014). The phylogenetic tree showed that, the basal architecture of the CPK gene family of three classes (monocot, dicot and lower eukaryotic plants) is conserved and emerged from a common ancestor. Significant sequence similarities exist among the CPKs, indicating that they are probably arose very recently via gene duplication with similar or overlapping functions. The orthologous genes are considered as evolutionary counter parts that must be derived from a common ancestor, while paralogs are homologous genes that evolved through duplication within the same genome (Chen et al., 2005). Paralogs tend to evolve due to new functions for better adaptation (Makarova et al., 2005; Wu et al., 2006). When duplication precedes speciation, each of the paralogs gives rise to a distinct line of orthologous descent (Vleeshouwers et al., 2001; Ting et al., 2004; Chauve et al., 2008). Conversely, when duplication occurs after a particular speciation event in one or both lineages independently, one-to-one orthologous relationships cannot be delineated in principle, resulting in co-orthologs (Li et al., 2010; Mahmood et al., 2012; Yan et al., 2012). The lineage specific expansion of paralogous gene families, which in some cases accounts for a sizable fraction of the genome, is considered as one of the major mechanisms of adaptation (Jordan et al., 2001; Lespinet et al., 2002). 


\section{A}

LuCPK2-1
CsatCPK1
OsCPK27
ThCPK2

LuCPK2-1

CsatCPK1

OsCPK27

ThCPK2

\section{LuCPK2-1 \\ CsatCPK1 \\ OsCPK27 \\ ThCPK2}

\section{Auto-inhibitory Domain}

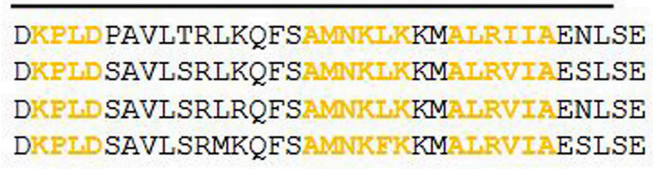

$2^{\text {nd }}$ EF-Hand

LKVGLKTFGAN
LKDGLRRFGAN
LKAGLERVGAN
LKAGLKRVGAN
LDESEIYDLMQAADNINNGAIDYPEFIAATLHLNKV

LNETEIKDLMQAAD FDNNGCIDYGEFIAATLHLNKA

MKESEIYQLMQAAD IDNSGT IDYGEFIAATLHLNKV

LKESEILDLMQAADVDNSGT IDYKEFIAATLHLNKI $1^{\text {st }} \mathrm{EF}-\mathrm{Hand}$

EEIAGLREMFRMIDTDNSGTITFEE EEIAGLKEMFKMIDTDNSGQITFEE EEIAGLKEMFKMMDTDNSGQINYEE EEIAGLKEMFKMIDADNSGQITFEE

\begin{tabular}{l}
$3^{\text {rd }}$ EF-Hand \\
\hline EREDRLLTTFSYF \\
GREDHLFAAFQYF \\
EREDHLYAAFQYF \\
EREDHLFAAFSYF
\end{tabular}

$4^{\text {th }}$ EF-Hand
MKA-VELEEMIREVDKDN--DGRIDYNEFVEMMQTSHS
IEN-VHLEDMIREVDQDN--DGRIDYNEFVAMMQKGNX-
IED-VRLEDMIGEVDQDN--DGRIDYNEFVAMMQKTTTG
VED-ARIEEMMRDVDQDK--DGRIDYNEFVAMMRSGNTK

B

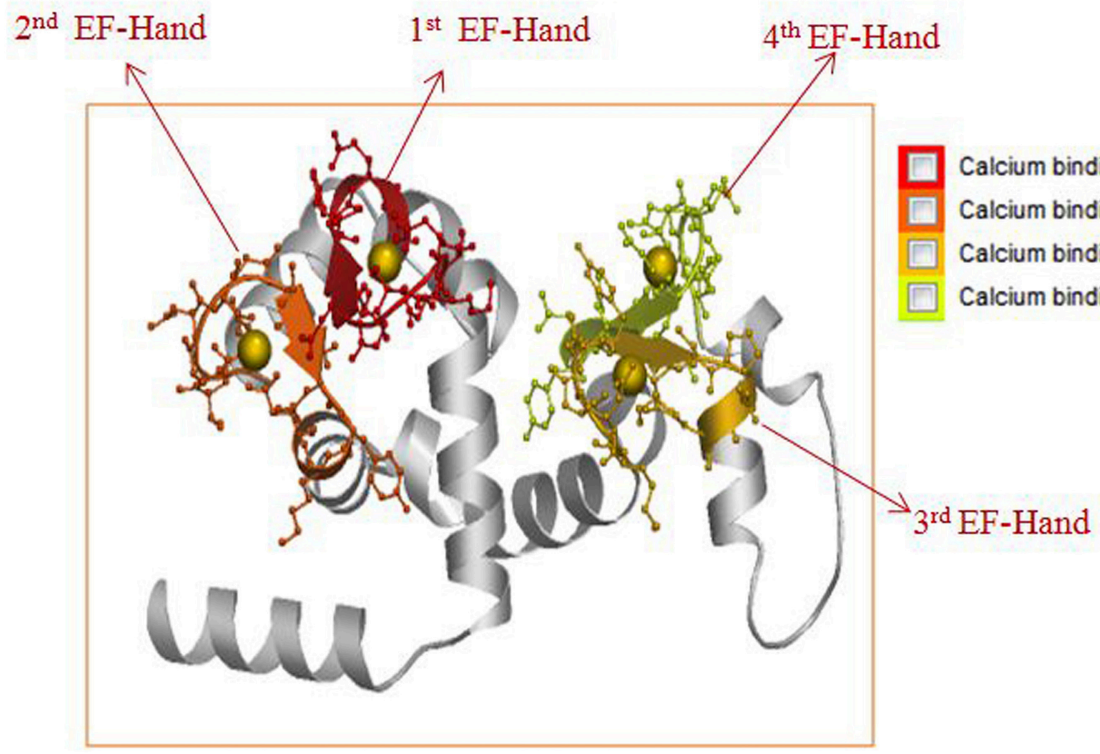

FIGURE 3 | (A) The presence of conserved domains and motifs in auto-inhibitory and EF-hand regions of calcium-dependent protein kinases (CPKs) in plants. The auto-inhibitory domain contains K-P-L-D, A-M-N-K-L-K, and A-L-R-I-I-A conserved sequences (orange). The EF-hand regions of the regulatory domain of CPK have $D-X-D$ (red) and D/E-E-L motifs (light blue). Higher plants contain four D-X-D motifs in their EF-hands, while lower eukaryotes have only two D-x-D and one D-X-X-E motif. Other motifs found in the EF-hands include E-E-I and E-E-L (green). The presence of the conserved motif E-E-I/x (green) at position 1, 2, and 3, as well as E-M-F at position 8, 9, and 10 (bold black) are first EF-hand specific. The E-x-E motif (dark red) at position 3, 4, and 5 is second EF-hand specific, while the x-E-D motif at position 3 and 4 (pink) is third EF-hand specific. The presence of conserved D/E at position 11 and 12 is fourth EF-hand specific. Some conserved D and E residues present in the EF-hand regions of plants are indicated in purple. Complete details regarding the conserved domains of CPKs can be found in the Supplementary Figures. (B) Three dimensional structure of the EF-hand domain of plant CPK (AtCPK1). The structure was created using the Swiss-Model workspace (http://swissmodel.expasy.org) for AtCPK1 as a representative sequence. The colored boxes in the bottom represent the presence of calcium binding motifs within the specific region of EF-hands. Regions ranging from amino acids 464-475, 500-511, 536-547, and 570-581 belong to the first, second, third and fourth EF-hands respectively. All calcium binding EF-hands start with the D-x-D motif. The starting regions of all calcium-binding EF-hands contain conserved D-x-D motif and ends with conserved glutamic acid (E). The conserved D-X-D motif present at position 14, 15, and 16 and conserved $E$ residue is present at position 25 in each EF-hand. Therefore, amino acids 14-25 of each EF-hand are assumed to play crucial roles in calcium binding activity. In conclusion, EF-hands contain conserved aspartic acid (D) and glutamic acid (E) residues, which may be critical to accessory signaling in calcium binding. 

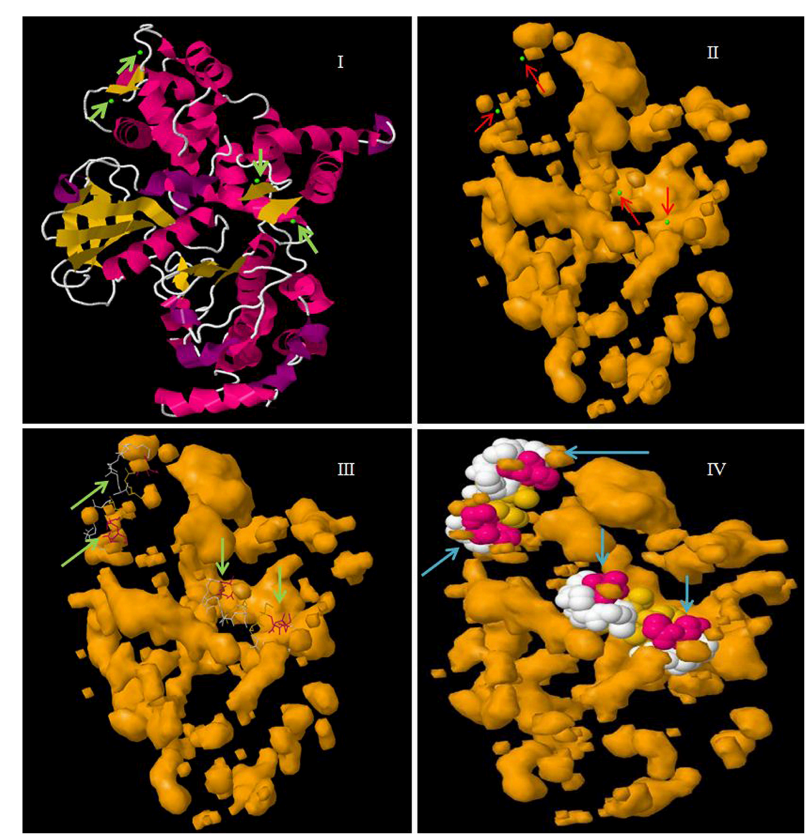

FIGURE 4 | Molecular structure of CPK protein showing four EF-hand domains. In the figure, (I) represents the secondary structure of CPK protein with calcium binding sites in green, (II) the cavity surface of CPK protein with calcium binding sites shown in green, (III) the $\mathrm{Ca}^{2+}$ ligand interaction with CPK protein, and (IV) a space fill view of the $\mathrm{Ca}^{2+}$ ligand interaction in cavity model of CPK protein. The molecular model was constructed in the Geno3D server using protein sequence of AtCPK1 as the query search.

\section{CPKs are Undergone Vivid Gene Duplication During the Course of Evolution}

The CPK gene family is characterized by the presence of several paralogs that share a significant level of homology. These closely related $C P K$ genes most likely emerged following a recent gene duplication event, which would explain why $C P K$ genes have not yet diversified much. In some cases, duplication may be due to diversification events or lineage specific. Gene duplication may increase due to auto-polyploidization, which is the most common mechanism of gene duplication in plants.

The genomes of C. subellipsoidea and M. pusila CCMP1545 contain only two $C P K$ genes, whereas O. lucimarinus contains only three $C P K$ genes, indicating no significant duplication of $C P K$ genes in these species. Another lower eukaryotic alga, $C$. reinhardtii, contains 14 CPK genes with several paralogs; while $V$. carteri has six $C P K$ with no paralogous genes, indicating that, gene duplication may have started from Chlamydomonas. The first land plant, $P$. patens, contains 25 CPK genes in its genome, including several paralogous genes; however, the pteridophyte $S$. moellendoffii contains only nine CPK genes (Banks et al., 2011; Baker et al., 2013). Although Picea abies has undergone vivid duplication (Morse et al., 2009; Mackay et al., 2012; Nystedt et al., 2013), we found that the model gymnosperm $P$. abies contains only $11 C P K$ with no paralogous genes. Only the genome of $P$. patens in bryophytes has been sequenced and confirmed to have undergone recent large scale duplication (Bisova et al.,
TABLE 3 | Protein myristoylation and palmitoylation are important post-translational modification events required for sub-cellular targeting of CPKs.

\begin{tabular}{|c|c|c|}
\hline SI No. & $\begin{array}{l}\text { Consensus myristoylation } \\
\text { and palmitoylationsite sequence }\end{array}$ & $\begin{array}{c}\text { No. of } \\
\text { CPK genes }\end{array}$ \\
\hline 1 & MGNC & 268 \\
\hline 2 & MGNCC & 201 \\
\hline 3 & MGC & 60 \\
\hline 4 & MGNTCV & 57 \\
\hline 5 & QFGTTYLC & 45 \\
\hline 6 & MGNCCR & 40 \\
\hline 7 & MGLC & 36 \\
\hline 8 & MGGC & 35 \\
\hline 9 & MGNNC & 26 \\
\hline 10 & MGSC & 26 \\
\hline 11 & MGNSC & 21 \\
\hline 12 & QFGTTFLC & 20 \\
\hline 13 & MGIC & 17 \\
\hline 14 & MGNCNAC & 16 \\
\hline 15 & MGQC & 15 \\
\hline 16 & MGNAC & 14 \\
\hline 17 & QFGTTYQC & 13 \\
\hline 18 & MGNVC & 12 \\
\hline 19 & MGVC & 12 \\
\hline 20 & MGNQC & 8 \\
\hline 21 & QFGVTYLC & 5 \\
\hline 22 & QFGITYLC & 5 \\
\hline 23 & VHLVMELC & 4 \\
\hline 24 & MGNCNTC & 4 \\
\hline 25 & MELC & 4 \\
\hline
\end{tabular}

Protein myristoylation is usually carried out in glycine (G) residues and is conserved at the second position (green). Similarly, protein palmitoylation is carried out in cysteine (C) residues (red). The 25 likely conserved consensus sequences of CPK palmitoylation sites found in this study are listed. The presence of $\mathrm{C}$ amino acid at position3, 4, and 5 plays a crucial role in CPK palmitoylation.

2005; Zimmer et al., 2008). Nevertheless, it is difficult to predict whether recent duplication events contributed to expansion of the $C P K$ family of other non-vascular plants.

\section{CPKs are Evolved by Balancing Selection}

Statistical analysis is very important to understand the significance of the study. Therefore, we used Tajima's relative rate test to analyze three samples (sequences) selected at random (Tajima, 1998). We repeated this analysis three times using different sequences. For all three cases, the $p$ value and $X^{2}$ - (Chi-square) test were found to be significant (Table 4).

Tajima's neutrality test ( $D$-test) was conducted to understand the polymorphism of CPKs (Tajima, 1989). We found that, Tajima's $D$-value for all CPKs is 5.269218 (Table 5). A negative Tajima's D signifies very low frequency of polymorphism relative to the expectation indicating expansion of population size by purifying selection. Similarly, a positive Tajima's D indicates a high level of polymorphism (Tajima, 1989; Fu and Li, 1993; 


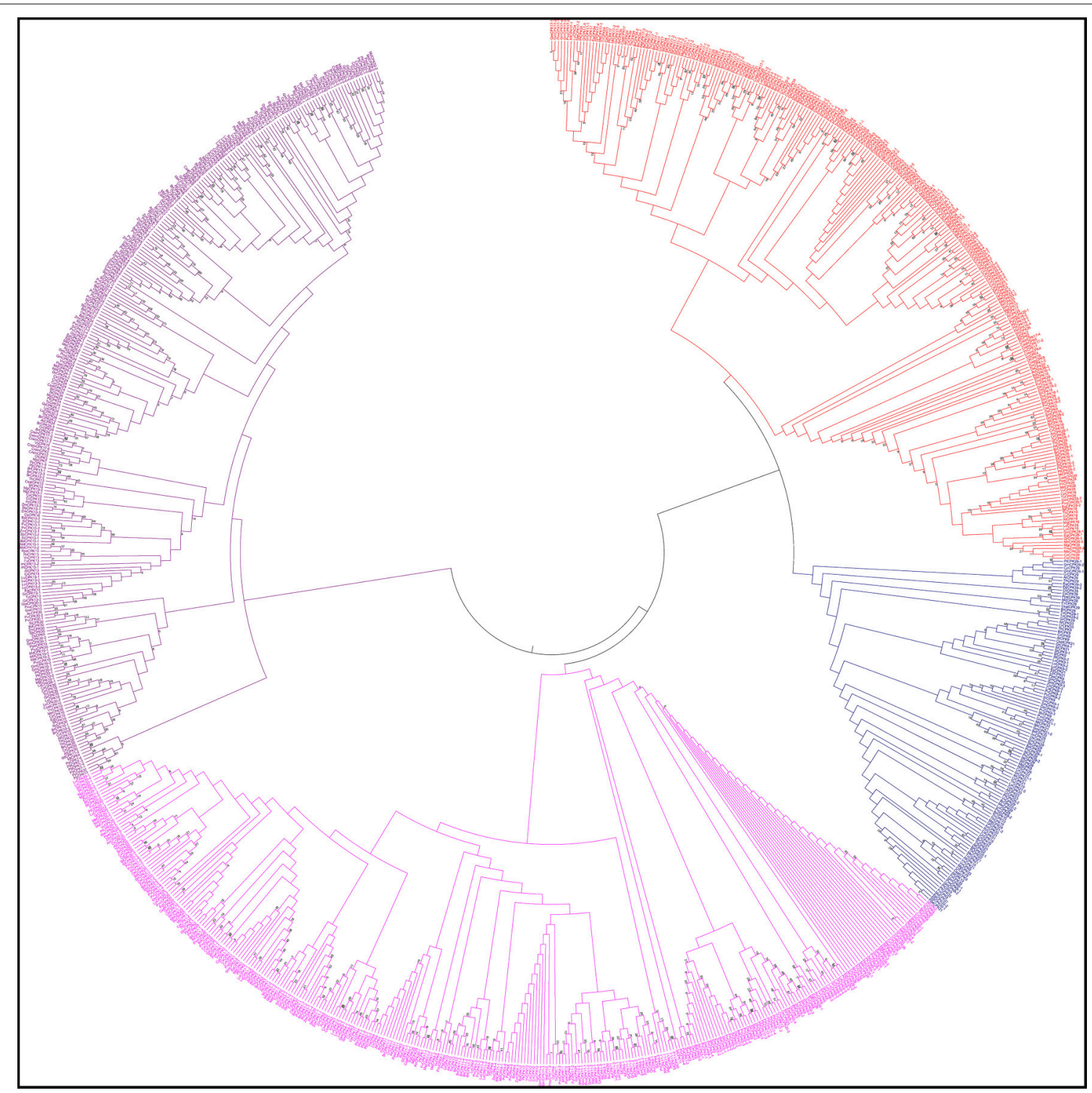

FIGURE 5 | Phylogenetic tree of calcium-dependent protein kinases (CPKs). The CPKs of monocots, dicots, green algae, bryophytes, pteridophytes, and gymnosperms were searched from different genome databases using CPK genes of Arabidopsis thaliana as queries. Identified sequences were only accepted if the corresponding proteins had serine/threonine protein kinase domain and four calcium binding EF-hand domains. A phylogenetic tree was constructed using Molecular Evolutionary Genetics Analysis 6 (MEGA 6) by neighbor joining method with 1000 bootstrap replicates. The constructed phylogenetic tree showed that, CPKs are clustered into four different groups: A (red), B (blue), C (fuschia), and D (purple).

Simonsen et al., 1995). The high level of polymorphism indicates decrease in population size by balancing selection. In the present study, the Tajima's $D$-value for all CPKs was 5.269218 (Table 5) which indicates that, plant CPK genes are undergoing balancing selection and hence decreasing in population size. A Tajima's D of zero $(D=0)$ indicates that, the average heterozygosity is equal to the number of segregating sites. This can be inferred as an observed variation similar to the expected variation, indicating that the population evolved in mutation-drift equilibrium. A Tajima's $(D<0)$ indicates greater lower average heterozygosity than the number of segregating sites and that there will be very rare alleles at low frequency. A Tajima's $D$-value $(D>0)$ indicates greater average heterozygosity than the number of segregating sites and multiple alleles presents at high frequency. This leads to balancing selection by sudden population contraction. A $D$ value greater than +2 or less than -2 is considered as significant; accordingly, the $D$-value in the present study is +5.269218 which is significant (Tajima, 1989; Fu and Li, 1993; Simonsen et al., 1995).

\section{CPK Genes are Differentially Expressed During Stress Conditions}

The expression analysis of some $B$. rapa $C P K$ genes treated with cold and heat/drought stress were analyzed. In cold 
TABLE 4 | Results of Tajima's test for 3 sequences in three replicate analyses.

\begin{tabular}{|c|c|c|c|}
\hline Configuration & $\begin{array}{c}\text { AtCPK18 } \\
\text { PpCPK16-3 } \\
\text { SmCPK16 }\end{array}$ & $\begin{array}{c}\text { ThCPK12 } \\
\text { OsCPK3 } \\
\text { CreinCPK17-6 }\end{array}$ & $\begin{array}{c}\text { GrCPK11-2 } \\
\text { OsCPK3 } \\
\text { CreinCPK17-6 }\end{array}$ \\
\hline $\begin{array}{l}\text { Identical sites in all three } \\
\text { sequences }\end{array}$ & 307 & 121 & 122 \\
\hline $\begin{array}{l}\text { Divergent sites in all three } \\
\text { sequences }\end{array}$ & 49 & 164 & 169 \\
\hline $\begin{array}{l}\text { Unique differences in } \\
\text { sequence } \mathrm{A}\end{array}$ & 66 & 23 & 22 \\
\hline $\begin{array}{l}\text { Unique differences in } \\
\text { sequence B }\end{array}$ & 33 & 57 & 54 \\
\hline $\begin{array}{l}\text { Unique differences in } \\
\text { sequence } C\end{array}$ & 29 & 75 & 73 \\
\hline$P$-value & 0.00091 & 0.00014 & 0.00024 \\
\hline$x^{2}$-test & 11.00 & 14.45 & 13.47 \\
\hline Degree of freedom & 1 & 1 & 1 \\
\hline
\end{tabular}

A P-value less than 0.05 is often used to reject the null hypothesis of equal rates between lineages. The analysis involved three amino acid sequences. All positions containing gaps and missing data were eliminated.

TABLE 5 | Results of Tajima's Neutrality Test.

\begin{tabular}{cccccc}
\hline $\boldsymbol{m}$ & $\boldsymbol{S}$ & $\boldsymbol{p}_{\mathbf{S}}$ & $\boldsymbol{\Theta}$ & $\boldsymbol{\pi}$ & $\boldsymbol{D}$ \\
\hline 950 & 24 & 1.000000 & 0.134532 & 0.427892 & 5.269218 \\
\hline
\end{tabular}

The analysis involved 950 amino acid sequences. All positions containing gaps and missing data were eliminated. There were a total of 24 positions in the final dataset. Evolutionary analyses were conducted in MEGA6.

$m$, number of sequences; $n$, total number of sites; $S$, number of segregating sites; $p_{S}$, $S / n ; \Theta, p_{S} / a_{1} ; \pi$, nucleotide diversity, and $D$ is the Tajima test statistic.

treated B. rapa, expression of $B r C P K 1$ was up-regulated at 2, 4 , and $12 \mathrm{~h}$ (Figure 6). Additionally, $B r C P K 2$ was up-regulated at 2 and $4 \mathrm{~h}$ and got down regulated at $12 \mathrm{~h}$. The $B r C P K 4$ was gradually up-regulated from 2 to $12 \mathrm{~h}$ (Figure 6). The expression of $B r C P K 5$ was up-regulated by more than 2-fold in all three time periods. This indicates that, $B r C P K 1, B r C P K 2$, $B r C P K 4$, and $B r C P K 5$ are cold stress responsive genes. The upregulation at 2 and $4 \mathrm{~h}$ time point indicates the early response of calcium signaling genes to cold stress. Down regulation of $B r C P K 2$ at $12 \mathrm{~h}$ indicates, this gene plays significant role in early stage of calcium signaling event and gradually its expression decreases at late stage. The $B r C P K 12$ was down regulated at 2 and $4 \mathrm{~h}$ and up-regulated at $12 \mathrm{~h}$; while BrCPK28-1 upregulated at $2 \mathrm{~h}$ and then gradually down regulatedat $12 \mathrm{~h}$ (Figure 6). We found that, the maximum number of $C P K$ genes were up-regulated in response to cold stress indicating that these genes play significant roles in cold stress response in $B$. rapa.

Expression analysis of $B$. rapa $C P K$ genes subjected to drought stress revealed dynamic responses (Figure 7). The $B r C P K 1$ down regulated in all three time periods similar to $B r C P K 4$ and $B r C P K 7$ (Figure 7). However, $B r C P K 8-1$ was up-regulated at $2 \mathrm{~h}$, then gradually down regulated. $B r C P K 12$ was up-regulated at all the three time points. Similarly, the maximum expression of $B r C P K 20$ was observed at $4 \mathrm{~h}$, when it was up-regulated by more than 4-fold relative to control. The BrCPK1 and $B r C P K 4$ was up-regulated in cold stress and down regulated in drought stress. These result indicates, $B r C P K s$ responds to cold and drought stress differently. Early studies show that, $C P K s$ are significantly modulated by cold, drought and salt stresses. The OsCPK4 was found to be induce under cold and drought stresses (Ray et al., 2007). The BrCPK4 significantly up-regulated at 4 and $12 \mathrm{~h}$ time point similar to OsCPK4. Rice seedlings grown under cold stress for $3 \mathrm{~h}$ shows induction of OsCPK4, OsCPK12, OsCPK15, and OsCPK21 (Ray et al., 2007). The BrCPK12 found to be down regulated at 2 and $4 \mathrm{~h}$ time point and later get upregulated at $12 \mathrm{~h}$ time point. This result shows that, $\mathrm{BrCPK} 4$ and $B r C P K 12$ are responsive to cold stress in time dependent manner. BrCPK7 shows up-regulation due to cold stress. The over expression line of $O s C P K 7$ shows enhanced tolerance to cold stress (Saijo et al., 2000). This shows that, $B r C P K 7$ also responds to cold stress and it's over expression might responsible for cold tolerance. Unlike cold stresses, CPKs are also highly modulated due to drought stresses too (Figure 7). The AtCPK3 and AtCPK6 regulate ABA mediated stomatal closure (Mori et al., 2006). Thus, up-regulation of $B r C P K 3-1$ and $B r C P K 6-1$ in drought stress might be directly linked to stomatal closure in ABA mediated manner. AtCPK6 over expression plant shows enhanced tolerant to drought stress (Xu et al., 2010). So, up-regulation of BrCPK6 in drought stress directly reflects its role in drought stress response.

\section{CONCLUSION AND FUTURE PERSPECTIVES}

The CPKs constitute a large multi-gene family in various plant species that play important roles in various physiological processes, including plant growth and development, as well as abiotic and biotic stress responses. ThCPKs also plays considerable roles in stress tolerance. Extensive efforts using integrative approaches have provided conclusive evidence that $C P K s$ are versatile and evolutionarily conserved genes that transduce $\mathrm{Ca}^{2+}$ signals as sensors. The CPKs are involved in a sophisticated $\mathrm{Ca}^{2+}$ signaling network via protein phosphorylation and coordinate dynamic cellular processes for plant growth and development. Further studies will lead to a better understanding of specific and redundant roles of CPKs and their conserved domains in different signaling networks. To fully elucidate the $\mathrm{Ca}^{2+}$-mediated signaling network, it is essential to establish cellular, molecular and genetic linkage with $\mathrm{Ca}^{2+}$ channels, transporters and pumps for spatio-temporal analysis of $C P K$ gene activation and translocation. In vivo activation of $C P K$ genes has been limited because of difficulties in maintaining required $\mathrm{Ca}^{2+}$ levels, which reflect the physiological state in cell extracts. Raising specific anti-phosphopeptide antibodies against CPK protein or their substrates would facilitate monitoring of CPK activation, while identification 

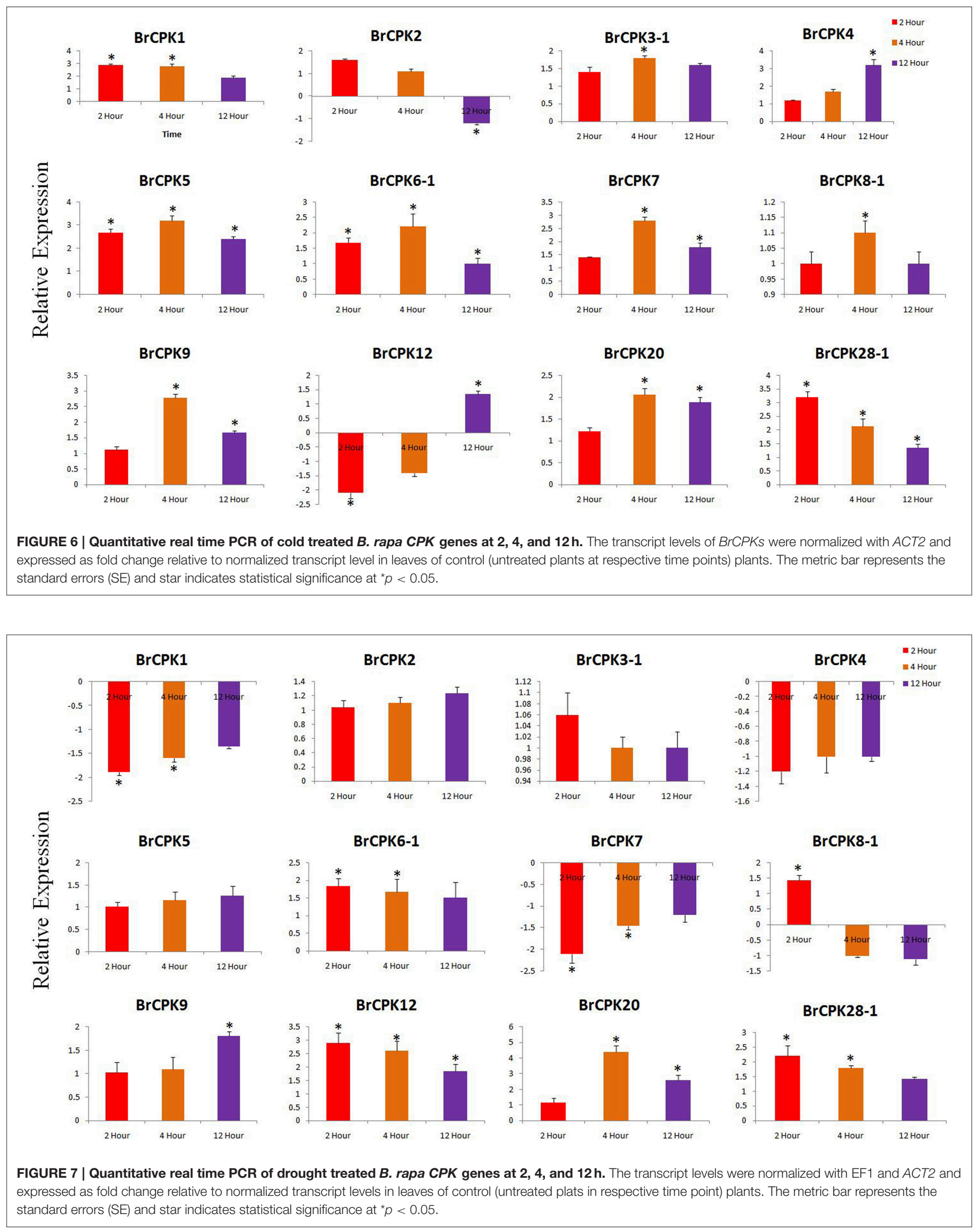
of downstream substrates and unique regulatory features of each isoform will provide insight into CPK signaling, enabling understanding of their integrated roles in diverse biological process.

\section{AUTHOR CONTRIBUTIONS}

TM conceived the idea, design the experiment analyzed data and drafted the manuscript. NM was analyzed the data. YM and HB revised the manuscript.

\section{REFERENCES}

Akashi, H., and Gojobori, T. (2002). Metabolic efficiency and amino acid composition in the proteomes of Escherichia coli and Bacillus subtilis. Proc. Natl. Acad. Sci. U.S.A. 99, 3695-3700. doi: 10.1073/pnas.062526999

Aravind, L., Mazumder, R., Vasudevan, S., and Koonin, E., V. (2002). Trends in protein evolution inferred from sequence and structure analysis. Curr. Opin. Struct. Biol. 12, 392-399. doi: 10.1016/S0959-440X(02)00334-2

Asano, T., Tanaka, N., Yang, G., Hayashi, N., and Komatsu, S. (2005). Genomewide identification of the rice calcium-dependent protein kinase and its closely related kinase gene families: comprehensive analysis of the CDPKs gene family in rice. Plant Cell Physiol. 46, 356-366. doi: 10.1093/pcp/pci035

Baker, C. R., Hanson-Smith, V., and Johnson, A. D. (2013). Following gene duplication, paralog interference constrains transcriptional circuit evolution. Science 342, 104-108. doi: 10.1126/science. 1240810

Banks, J. A., Nishiyama, T., Hasebe, M., Bowman, J. L., Gribskov, M., dePamphilis, C., et al. (2011). The Selaginella genome identifies genetic changes associated with the evolution of vascular plants. Science 332, 960-963. doi: 10.1126/science. 1203810

Bisova, K., Krylov, D. M., and Umen, J. G. (2005). Genome-wide annotation and expression profiling of cell cycle regulatory genes in chlamydomonas reinhardtii. Plant Physiol. 137, 475-491. doi: 10.1104/pp.104.0 54155

Boudsocq, M., and Sheen, J. (2013). CDPKs in immune and stress signaling. Trends Plant Sci. 18, 30-40. doi: 10.1016/j.tplants.2012.08.008

Chauve, C., Doyon, J.-P., and El-Mabrouk, N. (2008). Gene family evolution by duplication, speciation, and loss. J. Comput. Biol. 15, 1043-1062. doi: $10.1089 / \mathrm{cmb} .2008 .0054$

Chen, X., Zheng, J., Fu, Z., Nan, P., Zhong, Y., Lonardi, S., et al. (2005). Assignment of orthologous genes via genome rearrangement. IEEE/ACM Trans. Comput. Biol. Bioinform. 2, 302-315. doi: 10.1109/TCBB.2005.48

Cheng, S., Willmann, M. R., Chen, H., and Sheen, J. (2002). Calcium signaling through protein kinases. The Arabidopsis calcium-dependent protein kinase gene family. Plant Physiol. 129, 469-485. doi: 10.1104/pp.005645

Choi, W.-G., Toyota, M., Kim, S.-H., Hilleary, R., and Gilroy, and, S. (2014). From the cover: salt stress-induced $\mathrm{Ca} 2+$ waves are associated with rapid, longdistance root-to-shoot signaling in plants. Proc. Natl. Acad. Sci. U.S.A. 111, 6497-6502.

Clouse, S. D. (2011). Brassinosteroid signal transduction: from receptor kinase activation to transcriptional networks regulating plant development. Plant Cell 23, 1219-1230. doi: 10.1105/tpc.111.084475

Curran, A., Chang, I.-F., Chang, C.-L., Garg, S., Miguel, R. M., Barron, Y. D., et al. (2011). Calcium-dependent protein kinases from Arabidopsis show substrate specificity differences in an analysis of 103 substrates. Front. Plant Sci. 2:36. doi: 10.3389/fpls.2011.00036

Dadacz-Narloch, B., Beyhl, D., Larisch, C., López-Sanjurjo, E. J., Reski, R., Kuchitsu, K., et al. (2011). A novel calcium binding site in the slow vacuolar cation channel TPC1 senses luminal calcium levels. Plant Cell 23, 2696-2707. doi: 10.1105/tpc.111.086751

Davidson, D., and Gu, F. X. (2012). Materials for sustained and controlled release of nutrients and molecules to support plant growth. J. Agric. Food Chem. 60, 870-876. doi: 10.1021/jf204092h

\section{ACKNOWLEDGMENTS}

This study was carried out with the support of the "Forest Science and Technology Projects (Project no. S121414L030110)" provided by the Korea Forest Service.

\section{SUPPLEMENTARY MATERIAL}

The Supplementary Material for this article can be found online at: http://journal.frontiersin.org/article/10.3389/fpls.2015. 01146

Day, I. S., Reddy, V. S., Shad Ali, G., and Reddy, A. S. (2002). Analysis of EFhand-containing proteins in Arabidopsis. Genome Biol. 3:RESEARCH0056. doi: 10.1186/gb-2002-3-10-research0056

de Castro, E., Sigrist, C. J. A., Gattiker, A., Bulliard, V., Langendijk-Genevaux, P. S., Gasteiger, E., et al. (2006). ScanProsite: detection of PROSITE signature matches and ProRule-associated functional and structural residues in proteins. Nucleic Acids Res. 34, W362-W365. doi: 10.1093/nar/gkl124

Dodd, A. N., Kudla, J., and Sanders, D. (2010). The language of calcium signaling. Annu. Rev. Plant Biol. 61, 593-620. doi: 10.1146/annurev-arplant-070109104628

Fu, Y.-X, and Li, W.-H. (1993). Statistical tests of neutrality of mutations. Genetics 133, 693-709.

Goodstein, D. M., Shu, S., Howson, R., Neupane, R., Hayes, R. D., Fazo, J., et al. (2012). Phytozome: a comparative platform for green plant genomics. Nucleic Acids Res. 40, D1178-D1186. doi: 10.1093/nar/gkr944

Hamel, L.-P., Nicole, M.-C., Sritubtim, S., Morency, M.-J., Ellis, M., Ehlting, J., et al. (2006). Ancient signals: comparative genomics of plant MAPK and MAPKK gene families. Trends Plant Sci. 11, 192-198. doi: 10.1016/j.tplants. 2006.02.007

Hamel, L.-P., Sheen, J., and Séguin, A. (2014). Ancient signals: comparative genomics of green plant CDPKs. Trends Plant Sci. 19, 79-89. doi: 10.1016/j.tplants.2013.10.009

Harmon, A. C., Gribskov, M., Gubrium, E., and Harper, J. F. (2001). The CDPK superfamily of protein kinases. New Phytol. 151, 175-183. doi: 10.1046/j.14698137.2001.00171.x

Harmon, A. C., Gribskov, M., and Harper, J. F. (2000). CDPKs - a kinase for every Ca2+ signal? Trends Plant Sci. 5, 154-159. doi: 10.1016/S1360-1385(00)01577-6

Hrabak, E., Chan, C., and Gribskov, M. (2003). The Arabidopsis CDPKSnRK superfamily of protein kinases. Plant Physiol. 132, 666-680. doi: 10.1104/pp.102.011999

Huang, G.-T., Ma, S.-L., Bai, L.-P., Zhang, L., Ma, H., Jia, P., et al. (2012). Signal transduction during cold, salt, and drought stresses in plants. Mol. Biol. Rep. 39, 969-987. doi: 10.1007/s11033-011-0823-1

Hwang, I., Sze, H., and Harper, J. F. (2000). A calcium-dependent protein kinase can inhibit a calmodulin-stimulated Ca2+ pump (ACA2) located in the endoplasmic reticulum of Arabidopsis. Proc. Natl. Acad. Sci. U.S.A. 97, 6224-6229. doi: 10.1073/pnas.97.11.6224

Ito, T., Nakata, M., Fukazawa, J., Ishida, S., and Takahashi, Y. (2010). Alteration of substrate specificity: the variable N-terminal domain of tobacco $\mathrm{Ca}(2+)$ dependent protein kinase is important for substrate recognition. Plant Cell 22, 1592-1604. doi: 10.1105/tpc.109.073577

Jain, M., Khurana, P., Tyagi, A. K., and Khurana, J. P. (2008). Genome-wide analysis of intronless genes in rice and Arabidopsis. Funct. Integr. Genomics 8, 69-78. doi: 10.1007/s10142-007-0052-9

Jordan, I. K., Makarova, K. S., Spouge, J. L., Wolf, Y. I., and Koonin, E., V (2001). Lineage-specific gene expansions in bacterial and archaeal genomes. Genome Res. 11, 555-565. doi: 10.1101/gr.GR-1660R

Kanchiswamy, C. N., Mohanta, T. K., Capuzzo, A., Occhipinti, A., Verrillo, F., Maffei, M. E., et al. (2013). Differential expression of CPKs and cytosolic Ca2+ variation in resistant and susceptible apple cultivars (Malus $\mathrm{x}$ domestica) in response to the pathogen Erwinia amylovora and mechanical wounding. BMC Genomics 14:760. doi: 10.1186/1471-2164-14-760 
Kong, X., Lv, W., Jiang, S., Zhang, D., Cai, G., Pan, J., et al. (2013). Genome-wide identification and expression analysis of calcium-dependent protein kinase in maize. BMC Genomics 14:433. doi: 10.1186/1471-2164-14-433

Krouk, G., Ruffel, S., Gutiérrez, R. A., Gojon, A., Crawford, N. M., Coruzzi, G. M., et al. (2011). A framework integrating plant growth with hormones and nutrients. Trends Plant Sci. 16, 178-182. doi: 10.1016/j.tplants.201 1.02.004

Lamesch, P., Berardini, T. Z., Li, D., Swarbreck, D., Wilks, C., Sasidharan, R., et al. (2012). The Arabidopsis Information Resource (TAIR): improved gene annotation and new tools. Nucleic Acids Res. 40, D1202-D1210. doi: 10.1093/nar/gkr1090

Lawson, T., Davey, P. A., Yates, S. A., Bechtold, U., Baeshen, M., Baeshen, N., et al. (2014). C3 photosynthesis in the desert plant Rhazya stricta is fully functional at high temperatures and light intensities. New Phytol. 201, 862-873. doi: 10.1111/nph.12559

Lespinet, O., Wolf, Y. I., Koonin, E. V., and Aravind, L. (2002). The role of lineagespecific gene family expansion in the evolution of eukaryotes. Genome Res. 12, 1048-1059. doi: 10.1101/gr.174302

Li, Q., Li, L., Yang, X., Warburton, M., Bai, G., Dai, J., et al. (2010). Relationship, evolutionary fate and function of two maize co-orthologs of rice GW2 associated with kernel size and weight. BMC Plant Biol. 10:143. doi: 10.1186/1471-2229-10-143

Li, Y., Hao, P., Zheng, S., Tu, K., Fan, H., Zhu, R., et al. (2008). Gene expression module-based chemical function similarity search. Nucleic Acids Res. 36, e137. doi: 10.1093/nar/gkn610

Liu, W., Li, W., He, Q., Daud, M. K., Chen, J., and Zhu, S. (2014). Genome-wide survey and expression analysis of calciumdependent protein kinase in Gossypium raimondii. PLoS ONE 9:e98189. doi: 10.1371/journal.pone.0098189

Lu, S. X., and Hrabak, E. M. (2002). An arabidopsis calcium-dependent protein kinase is associated with the endoplasmic reticulum 1. Plant Physiol. 128, 1008-1021. doi: 10.1104/pp.010770

Luan, S. (2009). The CBL-CIPK network in plant calcium signaling. Trends Plant Sci. 14, 37-42. doi: 10.1016/j.tplants.2008.10.005

Mackay, J., Dean, J. F. D., Plomion, C., Peterson, D. G., Cánovas, F. M., Pavy, N., et al. (2012). Towards decoding the conifer giga-genome. Plant Mol. Biol. 80, 555-569. doi: 10.1007/s11103-012-9961-7

Mahmood, K., Webb, G., Song, J., Whisstock, J., and Konagurthu, A. (2012). Efficient large-scale protein sequence comparison and gene matching to identify orthologs and co-orthologs. Nucl. Acids Res. 40:e44. doi: $10.1093 / \mathrm{nar} / \mathrm{gkr} 1261$

Makarova, K. S., Wolf, Y. I., Mekhedov, S. L., Mirkin, B. G., and Koonin, E., V (2005). Ancestral paralogs and pseudoparalogs and their role in the emergence of the eukaryotic cell. Nucleic Acids Res. 33, 4626-4638. doi: 10.1093/nar/gki775

Martín, M. L., and Busconi, L. (2001). A rice membrane-bound calcium-dependent protein kinase is activated in response to low temperature. Plant Physiol. 125, 1442-1449. doi: 10.1104/pp.125.3.1442

Matos, D. A., Cole, B. J., Whitney, I. P., MacKinnon, K. J.-M., Kay, S. A., and Hazen, S. P. (2014). Daily changes in temperature, not the circadian clock, regulate growth rate in Brachypodium distachyon. PLoS ONE 9:e100072. doi: 10.1371/journal.pone.0100072

Mohanta, T. K., Arora, P. K., Mohanta, N., Parida, P., and Bae, H. (2015a). Identification of new members of the MAPK gene family in plants shows diverse conserved domains and novel activation loop variants. BMC Genomics 16:58. doi: 10.1186/s12864-015-1244-7

Mohanta, T., and Bae, H. (2015). Functional genomics and signaling events in mycorrhizal symbiosis. J. Plant Interact. 10, 21-40. doi: 10.1080/17429145.2015.1005180

Mohanta, T. K., and Mohanta, N. (2013). Genome wide identification of auxin efflux carrier gene family in physcomitrella patens. J. Biotechnol. Sci. 1, 54-64.

Mohanta, T. K., Mohanta, N., Mohanta, Y. K., Parida, P., and Bae, H. (2015b). Genome-wide identification of Calcineurin B-Like (CBL) gene family of plants reveals novel conserved motifs and evolutionary aspects in calcium signaling events. BMC Plant Bol. 15:189. doi: 10.1186/s12870015-0543-0

Mohanta, T. K., Occhipinti, A., Atsbaha Zebelo, S., Foti, M., Fliegmann, J., Bossi, S., et al. (2012). Ginkgo biloba responds to herbivory by activating early signaling and direct defenses. PLoS ONE 7:e32822. doi: 10.1371/journal.pone.0032822
Mohanta, T., Malnoy, M., Mohanta, N., and Kanchiswamy, C. (2014). In-silico identification and phylogenetic analysis of auxin efflux carrier gene family in Setaria italica L. Afr. J. Biotechnol. 13, 211-225. doi: 10.5897/AJB2014. 13617

Mori, I. C., Murata, Y., Yang, Y., Munemasa, S., Wang, Y. F., Andreoli, S., et al. (2006). CDPKs CPK6 and CPK3 function in ABA regulation of guard cell Stype anion- and $\mathrm{Ca} 2+-$ permeable channels and stomatal closure. PLoS Biol. 4:e327. doi: 10.1371/journal.pbio.0040327

Morse, A. M., Peterson, D. G., Islam-Faridi, M. N., Smith, K. E., Magbanua, Z., Garcia, S. A., et al. (2009). Evolution of genome size and complexity in Pinus. PLoS ONE 4:e4332. doi: 10.1371/journal.pone.0004332

Nystedt, B., Street, N. R., Wetterbom, A., Zuccolo, A., Lin, Y.-C., Scofield, D. G., et al. (2013). The Norway spruce genome sequence and conifer genome evolution. Nature 497, 579-584. doi: 10.1038/nature12211

Ouyang, S., Zhu, W., Hamilton, J., Lin, H., Campbell, M., Childs, K., et al. (2007). The TIGR Rice Genome Annotation Resource: improvements and new features. Nucleic Acids Res. 35, D883-D887. doi: 10.1093/nar/gk1976

Palenik, B., Grimwood, J., Aerts, A., Rouzé, P., Salamov, A., Putnam, N., et al. (2007). The tiny eukaryote Ostreococcus provides genomic insights into the paradox of plankton speciation. Proc. Natl. Acad. Sci. U.S.A. 104, 7705-7710. doi: 10.1073/pnas.0611046104

Ray, S., Agarwal, P., Arora, R., Kapoor, S., and Tyagi, A. K. (2007). Expression analysis of calcium-dependent protein kinase gene family during reproductive development and abiotic stress conditions in rice (Oryza sativa L. ssp. indica). Mol. Genet. Genomics 278, 493-505. doi: 10.1007/s00438-0070267-4

Reddy, A. S. N., Ali, G. S., Celesnik, H., and Day, I. S. (2011). Coping with stresses: roles of calcium- and calcium/calmodulin-regulated gene expression. Plant Cell 23, 2010-2032. doi: 10.1105/tpc.111.084988

Ren, J., Wen, L., Gao, X., Jin, C., Xue, Y., and Yao, X. (2008). CSS-Palm 2.0: an updated software for palmitoylation sites prediction. Protein Eng. Des. Sel. 21, 639-644. doi: 10.1093/protein/gzn039

Rensing, S. A., Lang, D., Zimmer, A. D., Terry, A., Salamov, A., Shapiro, H., et al. (2008). The Physcomitrella genome reveals evolutionary insights into the conquest of land by plants. Science 319, 64-69. doi: 10.1126/science.11 50646

Saijo, Y., Hata, S., Kyozuka, J., Shimamoto, K., and Izui, K. (2000). Overexpression of a single $\mathrm{Ca} 2+$-dependent protein kinase confers both cold and salt/drought tolerance on rice plants. Plant J. 23, 319-327. doi: 10.1046/j.1365313x.2000.00787.x

Schlicker, A., Domingues, F. S., Rahnenführer, J., and Lengauer, T. (2006). A new measure for functional similarity of gene products based on Gene Ontology. BMC Bioinformatics 7:302. doi: 10.1186/1471-2105-7-302

Schmittgen, T. D., and Livak, K. J. (2008). Analyzing real-time PCR data by the comparative CT method. Nat. Protoc. 3, 1101-1108. doi: 10.1038/nprot.2 008.73

Schulz, P., Herde, M., and Romeis, T. (2013). Calcium-dependent protein kinases: hubs in plant stress signaling and development. Plant Physiol. 163, 523-530. doi: 10.1104/pp.113.222539

Simonsen, K. L., Churchill, G. A., and Aquadro, C. F. (1995). Properties of statistical tests of neutrality for DNA polymorphism data. Genetics 141, 413-429.

Smotrys, J. E., and Linder, M. E. (2004). Palmitoylation of intracellular signaling proteins: regulation and function. Annu. Rev. Biochem. 73, 559-587. doi: 10.1146/annurev.biochem.73.011303.073954

Sulmann, S., Dell'orco, D., Marino, V., Behnen, P., and Koch, K.-W. (2014). Conformational changes in calcium-sensor proteins under molecular crowding conditions. Chemistry 20, 6756-6762. doi: 10.1002/chem.201402146

Tajima, F. (1989). Statistical method for testing the neutral mutation hypothesis by DNA polymorphism. Genetics 595, 585-595.

Tajima, F. (1998). Simple methods for testing the molecular evolutionary clock hypothesis. Genet. Soc. Am. 135, 599-607.

Tamura, K., Stecher, G., Peterson, D., Filipski, A., and Kumar, S. (2013). MEGA6: molecular evolutionary genetics analysis version 6.0. Mol. Biol. Evol. 30, 2725-2729. doi: 10.1093/molbev/mst197

Tena, G., Boudsocq, M., and Sheen, J. (2011). Protein kinase signaling networks in plant innate immunity. Curr. Opin. Plant Biol. 14, 519-529. doi: 10.1016/j.pbi.2011.05.006 
Thornton, J. W., and DeSalle, R. (2000). Gene family evolution and homology: genomics meets phylogenetics. Annu. Rev. Genomics Human Genet. 1, 41-73. doi: 10.1146/annurev.genom.1.1.41

Ting, C.-T., Tsaur, S.-C., Sun, S., Browne, W. E., Chen, Y.-C., Patel, N. H., et al. (2004). Gene duplication and speciation in Drosophila: evidence from the Odysseus locus. Proc. Natl. Acad. Sci. U.S.A. 101, 12232-12235. doi: 10.1073/pnas.0401975101

Tuteja, N., and Mahajan, S. (2007). Calcium signaling network in plants. Plant Signal. Behav. 2, 79-85. doi: 10.4161/psb.2.2.4176

Valmonte, G. R., Arthur, K., Higgins, C. M., and Macdiarmid, R. M. (2014). Calcium-dependent protein kinases in plants: evolution, expression and function. Plant Cell Physiol. 55, 551-569. doi: 10.1093/pcp/pct200

Vleeshouwers, V. G., Martens, A., van Dooijeweert, W., Colon, L. T., Govers, F., and Kamoun, S. (2001). Ancient diversification of the Pto kinase family preceded speciation in Solanum. Mol. Plant Microbe Interact. 14, 996-1005. doi: 10.1094/MPMI.2001.14.8.996

Wasternack, C., and Hause, B. (2013). Jasmonates: biosynthesis, perception, signal transduction and action in plant stress response, growth and development. An update to the 2007 review in Annals of Botany. Ann. Bot. 111, 1021-1058. doi: $10.1093 / \mathrm{aob} / \mathrm{mct} 067$

Weljie, A. M., Robertson, K. M., and Vogel, H. J. (2003). Conformational changes in the $\mathrm{Ca} 2+-$-regulatory region from soybean calcium-dependent protein kinase-alpha: fluorescence resonance energy transfer studies. J. Biol. Chem. 278, 43764-43769. doi: 10.1074/jbc.M306799200

Wright, M. W., and Bruford, E. A. (2006). Human and orthologous gene nomenclature. Gene 369, 1-6. doi: 10.1016/j.gene.2005.10.029

Wu, F., Mueller, L. A., Crouzillat, D., Pétiard, V., and Tanksley, S. D. (2006). Combining bioinformatics and phylogenetics to identify large sets of singlecopy orthologous genes (COSII) for comparative, evolutionary and systematic studies: a test case in the euasterid plant clade. Genetics 174, 1407-1420. doi: 10.1534/genetics.106.062455
Xu, J., Tian, Y. S., Peng, R. H., Xiong, A. S., Zhu, B., Jin, X. F., et al. (2010). AtCPK6, a functionally redundant and positive regulator involved in salt/drought stress tolerance in Arabidopsis. Planta 231, 1251-1260. doi: 10.1007/s00425-0101122-0

Yan, Y. L., Bhattacharya, P., He, X. J., Ponugoti, B., Marquardt, B., Layman. J., et al. (2012). Duplicated zebrafish co-orthologs of parathyroid hormone-related peptide (PTHrP, Pthlh) play different roles in craniofacial skeletogenesis. J. Endocrinol. 214, 421-435. doi: 10.1530/JOE-12-0110

Zhao, Y., Pokutta, S., Maurer, P., Lindt, M., Franklin, R. M., and Kappes, B. (1994). Calcium-binding properties of a calcium-dependent protein kinase from Plasmodium falciparum and the significance of individual calcium-binding sites for kinase activation. Biochemistry 33, 3714-3721. doi: 10.1021/bi00178a031

Zimmer, S. L., Fei, Z., and Stern, D. B. (2008). Genome-based analysis of Chlamydomonas reinhardtii exoribonucleases and poly(A) polymerases predicts unexpected organellar and exosomal features. Genetics 179, 125-136. doi: 10.1534/genetics.107.086223

Zuo, R., Hu, R., Chai, G., Xu, M., Qi, G., Kong, Y., et al. (2013). Genomewide identification, classification, and expression analysis of CDPK and its closely related gene families in poplar (Populus trichocarpa). Mol. Biol. Rep. 40, 2645-2662. doi: 10.1007/s11033-012-2351-z

Conflict of Interest Statement: The authors declare that the research was conducted in the absence of any commercial or financial relationships that could be construed as a potential conflict of interest.

Copyright (c) 2015 Mohanta, Mohanta, Mohanta and Bae. This is an open-access article distributed under the terms of the Creative Commons Attribution License (CC $B Y$ ). The use, distribution or reproduction in other forums is permitted, provided the original author(s) or licensor are credited and that the original publication in this journal is cited, in accordance with accepted academic practice. No use, distribution or reproduction is permitted which does not comply with these terms. 